\title{
Editorial
}

\section{Las bibliotecas populares y obreras como objetos de la historia}

Doi: $10.25100 /$ hye.v $14 i 51.6982$

El presente dosier, que reúne trabajos sobre la historia de las bibliotecas populares y obreras en Argentina y Brasil, es el resultado de un proceso de renovación historiográfica que se inició en la década de los ochenta en la historia del libro. En aquel entonces, tuvieron lugar diferentes debates y propuestas propedéuticas que, con diferentes grados de consenso, tendieron a definir esa disciplina en un nuevo arco metodológico y conceptual identificado como Historia de la Lectura. De forma progresiva estas discusiones se integraron a las tradiciones imperantes en América Latina hasta convertir este ámbito de trabajo en uno de los más prolíficos de las últimas tres décadas en materia de indagaciones histórico-culturales. En este contexto, perdió vigencia la antigua manera de entender la historia de las bibliotecas, que en sus largos años de predominio había acumulado reseñas descriptivas de los eventos institucionales, con mayores o menores niveles de relación con los procesos culturales de los que fueron parte. Contrariamente, en la actualidad se registra una disposición a pensar estas instituciones como dispositivos, esto es: como una red que relaciona y pone en movimiento discursos sobre la lectura, políticas públicas, apuestas editoriales, intervenciones intelectuales, mercados del libro, formación de lectores, sociabilidad asociativa, aspiraciones sociales, encuentros de lectura, pautas de civilidad y procesos bibliotecarios, entre otros aspectos que cabría explicar e interpretar.

Al pensar de forma conjunta los artículos dedicados a la Argentina que se inscriben en esta entrega surgen algunas constataciones que, consideradas en perspectiva, pueden contribuir a calibrar un objeto de conocimiento historiográfico que consolide sus fases conceptuales, metodológicas y 
comprensivas. En este sentido, la primera observación de rigor remite a la producción social y cognitiva de estas formaciones bibliotecarias singulares y, por lo mismo, a la exigencia que requiere recapitular, clasificar, ordenar e interpretar el archivo que testimonia la historia de las bibliotecas y, al mismo tiempo, la historia de los procesos de emergencia y prolongación de la institución biblioteca, en el sentido que la tradición filosófica francesa del siglo XX le dio al término institución, es decir, no como organización singular o conjunto de tales, sino como la sucesión de acontecimientos de potencia durable que funda una experiencia social sobre la cual se asientan otras que le son venideras y que solo en ella adquieren significado. De este dosier puede extraerse una colección documental inicial: de un lado se extienden los vestigios que dejaron a su paso los que supieron hacer las bibliotecas: actas de comisiones directivas, registros de lectores, estadísticas de préstamos, reglamentos, estatutos, memorias de gestión, libros de contabilidad, planos, fotografías, publicaciones, muebles y objetos de decoración. Las caras materiales y simbólicas impresas en esas presencias aluden a una representación de lo que fueron y quisieron ser. De otro, se ubican los testimonios producidos por el Estado, en sus diferentes jurisdicciones: leyes, decretos, reglamentos, protocolos, informes de inspección, inversiones de distinta índole (subsidios, libros, viáticos, etc.), estadísticas de bibliotecas, censos, revistas de la especialidad, eventos, audiciones de radio. En términos generales, el Estado se relacionó con las bibliotecas populares y obreras mediante la elaboración de una malla procedimental generadora de conocimiento y haceres de y sobre bibliotecas, que a su tiempo y alternativamente permitió alentar, controlar, direccionar, condicionar. Finalmente, se encuentran unas producciones discursivas que, por una parte, refieren a intenciones testimoniales o ficcionales, como las notas periodísticas o los fragmentos que pueden hallarse en memorias biográficas o escenas literarias; por otra, atañen a la profesionalización progresiva del saber sobre bibliotecas y se expresan en polémicas, artículos de revistas, ensayos y monografías. La reunión de esta bibliografía constata la 
emergencia de un campo bibliotecario que, al expandirse, modificó las prácticas y los ritmos en estas organizaciones.

La colección de esos documentos, cuyo valor reside en la reunión que le otorga significado y en el poder de evocación que sustentan, remite a la institución de la biblioteca. En Argentina, la fundación de la Biblioteca Pública de Buenos Aires en 1810 significó un pasaje elemental: la disposición pública de un conjunto de obras que, con anterioridad, se encontraban en manos privadas o bajo la administración de la Iglesia Católica. Esa transformación, que no era un hito aislado en el contexto bibliotecario internacional, contaba con unos antecedentes muy modestos en cuanto a emprendimientos que tuvieran como objeto de realización el uso público del libro. El efecto de biblioteca que se generó desde entonces se mantuvo en el horizonte de ideas culturales de la élite letrada, aunque durante medio siglo los alcances de la medida no se multiplicaron ni rebasaron el sector social que le había dado origen. En 1870 ese estancamiento comenzó a cambiar. Y este cambio fue brusco, radical: a partir de una ley de fomento que dispuso el Estado nacional se crearon cerca de cien bibliotecas populares, distribuidas entre las distintas provincias del país. Si es dable señalar que muchas de esas creaciones finalizaron una vez que el mismo Estado retiró las subvenciones en 1876, es legítimo sostener que durante este interregno se produjo un fenómeno de institución, es decir, la inscripción de la biblioteca en el espacio público y en el imaginario social. El siglo XX proporcionó experiencias sociales de muy distinto cariz ideológico, político y cultural. Aun cuando muchas de las organizaciones consideradas de modo singular tuvieron trayectorias zigzagueantes y, en ciertos casos, devenires trágicos; aun cuando el Estado no acompañó en la manera que la demanda social lo exigía; aun cuando la industria cultural puso a disposición de las personas más y más productos para ocupar el tiempo libre; la resultante de esa prolongación en el tiempo creó un consenso bibliotecario y de lectura que superó las posiciones antagónicas que esa pluralidad de anclajes diferenciales supuso.

El archivo y la institución son dos constataciones que, como quedó dicho, pueden extraerse de la lectura del presente dosier. 
Existe, además, una tercera comprobación que la lectura de este conjunto de trabajos permite hacer, y que aparece con claridad en forma de pregunta: ¿qué elementos hicieron posible que unas creaciones muy modestas hayan alcanzado semejante presencia social, a la vez perdurable y creciente?

En primer término, deben considerarse las relaciones de continuidad y diferencia que se establecieron entre las bibliotecas populares y las bibliotecas obreras. Ninguno de los estudios que aquí se presentan dejan de indicar, cada uno a su manera, el modo en que esas relaciones se sucedieron. Por supuesto: la intensidad de la diferenciación es más perceptible en el período entre siglos y bajo el signo del anarquismo que en las décadas de los veinte, treinta o cuarenta bajo la participación socialista. Pero, aun así, muchos de los dilemas bibliotecarios que enfrentaron aquellos militantes libertarios, como la cuestión de los horarios de apertura, la selección de la lectura o la elección del responsable o mediador, fueron conceptual y técnicamente los mismos que en cualquier otro tipo de biblioteca, solo que se resolvieron de diferente manera o asumieron formas singulares. La cuestión que se plantea, a todas luces, tiene que ver con el modo en que las izquierdas produjeron un cúmulo de objetivaciones bibliotecarias de tal índole que, en ese acto creativo, aseguraron la permanencia de estas instituciones en el tiempo y, al hacerlo, transformaron la noción misma de biblioteca.

En segundo lugar, aparece con notoriedad la cuestión del Estado. Una lectura atenta de los artículos revela -además del ya comentado archivo producido desde su estructura- la presencia de una política pública en relación con las bibliotecas. Si bien es notable que el Estado se ausentó durante casi cuarenta años entre el final del siglo XIX y 1910 -o cabría decir, con más propiedad, que atendió a otras formaciones bibliotecarias, como las de la cultura científica-, ningún proyecto heurístico que procure abordar a las bibliotecas populares y obreras como objeto de conocimiento puede prescindir de este elemento analítico. En el dosier hay algunas claves para desarrollar esta historia. Por una parte, se detecta la siempre prolífica cuestión política de la autonomía y el control, representada por los resortes estratégicos elaborados por el Estado y las tácticas de acoplamiento o distancia generadas por las asociaciones. En coyunturas específicas, 
especialmente bajo conducciones autoritarias o dictatoriales, este tópico se vuelve determinante. Por otra, se observa una evaluación de las intervenciones estatales identificadas con la pedagogía discursiva que este dispuso o impuso, así como también el modo en que las asociaciones hicieron uso de ellas. Por último, se percibe un interés en el factor económico bajo dos modalidades diferentes: una, que atañe a la inversión pública directa sobre el campo; otra, que alude a las decisiones macroeconómicas que, de manera alternativa, no solo incidieron en dicha variable, sino que además condicionaron la administración de las entidades y, desde ya, la vida cotidiana de los asociados.

En tercer orden, las investigaciones que aquí se presentan, se trate de bibliotecas obreras o populares, insisten todas en la cuestión fundamental de la sociabilidad y, junto a ella, la consolidación de un sentimiento hacia la lectura y la biblioteca como espacio material de reunión y de visita. Al cimentar y prolongar la creencia en el valor moral, político, sentimental y recreativo de los libros -junto o a distancia de la acción que el Estado acometió en este plano-, el conjunto de dirigentes sociales comprometidos con ese efecto emprendió una serie de tareas que, a lo largo del dosier, se observan en la definición de los catálogos, en las prácticas de ordenamiento bibliotecológico e institucional y, por último, en la estimulación de acontecimientos que multiplicaron las ocasiones de encuentro entre los lectores. En estos tres planos, las bibliotecas compartieron un horizonte de saberes semejantes y, por lo mismo, habilitaron un grupo de prácticas similares. La singularidad que asumió cada una de estas variantes condicionó el modo en que estas organizaciones sociales definieron su público.

Las claves expuestas hasta aquí pueden guiar la lectura de la presente compilación de artículos, aunque existen, desde ya, otras variables con las cuales es posible cruzar los textos. Ordenados diacrónicamente por sus cortes temporales, el primero de los seis estudios que siguen, a cargo de quién suscribe, procura realizar un balance historiográfico de lo que se publicó sobre la historia de las bibliotecas populares y obreras hasta la presentación de este dosier. En la intervención siguiente, «La creación de bibliotecas durante el apogeo del anarquismo argentino (1898-1905)», Eugenia 
Sik analiza las iniciativas de los grupos libertarios a través de un minucioso relevamiento de noticias sobre el tema en el periódico La Protesta (Humana) quele permiten reconstruir, entre otros aspectos, la manera en que estos grupos entendieron y dieron sentido a las bibliotecas. Con la investigación de María de los Ángeles Lanzillotta y Micaela Oviedo, «Difundir cultura e ilustración”. Las bibliotecas populares en la trama de la sociabilidad de las poblaciones pampeanas (1905-1955)», salimos al encuentro de los modos de desarrollo que este tipo de instituciones adquirieron fuera de las áreas metropolitanas y, al hacerlo, encontramos nuevos marcos para pensar las continuidades y las diferencias entre los centros urbanos y las poblaciones emergentes. En cuarto lugar aparece «Miradas de inspección: las bibliotecas populares del partido de La Plata según los informes de la Comisión Protectora (1919-1945)», de Ayelén Fiebellkorn. En este estudio la autora presenta, mediante un trabajo de archivo en los legajos de la Comisión Nacional de Bibliotecas Populares, el modo en que el Estado elaboró un saber sobre las bibliotecas a través de una serie de agentes que recorrieron las instituciones detallando juicios sobre lo que consideraron las buenas y las malas prácticas. En «La Biblioteca Popular Juventud Moderna. Teatro, sindicatos y sociabilidad. Mar del Plata, Argentina, 1939-1947”, Milagros Dolabani analiza la vigorosa sociabilidad que se gestó sobre esta institución, al focalizar el interés en las actividades del grupo filodramático y, al hacerlo, constata el modo en que el espacio bibliotecario se trasforma en un punto de encuentro y realización social, política y artística allende los objetivos propios que impone la lectura. Finalmente, el dosier se cierra con «Veinte años de memorias: el servicio bibliotecario de "La Vigil" (1956-1976)», en el que Natalia García expone un trabajo panorámico mediante el cual se percibe el modo en que una trayectoria institucional singular se entrecruza con la coyuntura histórica general. En este caso, se atestiguan distintas fases de crecimiento entre los años cincuenta y sesenta, para luego iniciar un lento declive en los setenta y acabar, brusca y trágicamente, con la intervención propiciada por el gobierno militar. El estudio nos deja a las puertas de asociar una historia y una sociología de las bibliotecas populares y obreras. 
Un párrafo específico amerita el estudio de Nelson Schapochnik: «Livros e leitura para o povo: ascensão e decadência da Bibliotecas Populares no Império Brasileiro $(1870-1889) »$. El ensayo panorámico que propone el autor caracteriza la época fundacional de las bibliotecas populares en Brasil. A través de una serie de entradas temáticas y distintas variables de análisis (cuantitativas y cualitativas), Schapochnik reconstruye una historia cuyos hitos no distan de la historia de las bibliotecas populares en Argentina. La construcción de una moral sobre la lectura, el uso de figuras emblemáticas como Benjamín Franklin, la participación de los sectores mesocráticos, la disputa por la formación sentimental del pueblo y la intervención de las agencias estatales en la construcción de una política pública de la lectura son, entre otras cuestiones, los tópicos que habilitarían a escribir una historia en perspectiva latinoamericana. De manera que este texto no solo agrega un conocimiento sobre los procesos bibliotecarios en Brasil, sino que además invita a pensar en la formación de un proyecto heurístico que promete grandes resultados.

Sin más preámbulo que el presente, invitamos al lector a recorrer estas investigaciones y, con ello, a descubrir las potencialidades de un objeto de conocimiento que está en construcción.

Javier Planas

Universidad Nacional de La Plata

(Argentina) 